NASA Contractor Report 3790

\title{
Creep-Rupture Reliability Analysis
}

Alonso Peralta-Duran and Paul H. Wirsching

GRANT NAG3-41

MARCH 1984

LOAN COPY: RETURN TO AFWL TECHNICAL LIBRARY KIRTLAND AFB, N.M. 87117 
NASA Contractor Report 3790

\section{Creep-Rupture Reliability Analysis}

Alonso Peralta-Duran and Paul H. Wirsching

The University of Arizona

Tucson, Arizona

Prepared for

Lewis Research Center under Grant NAG3-41

\section{N/SA}

National Aeronautics and Space Administration

Scientific and Technical Information Office 


\section{LIST OF SYMBOLS}

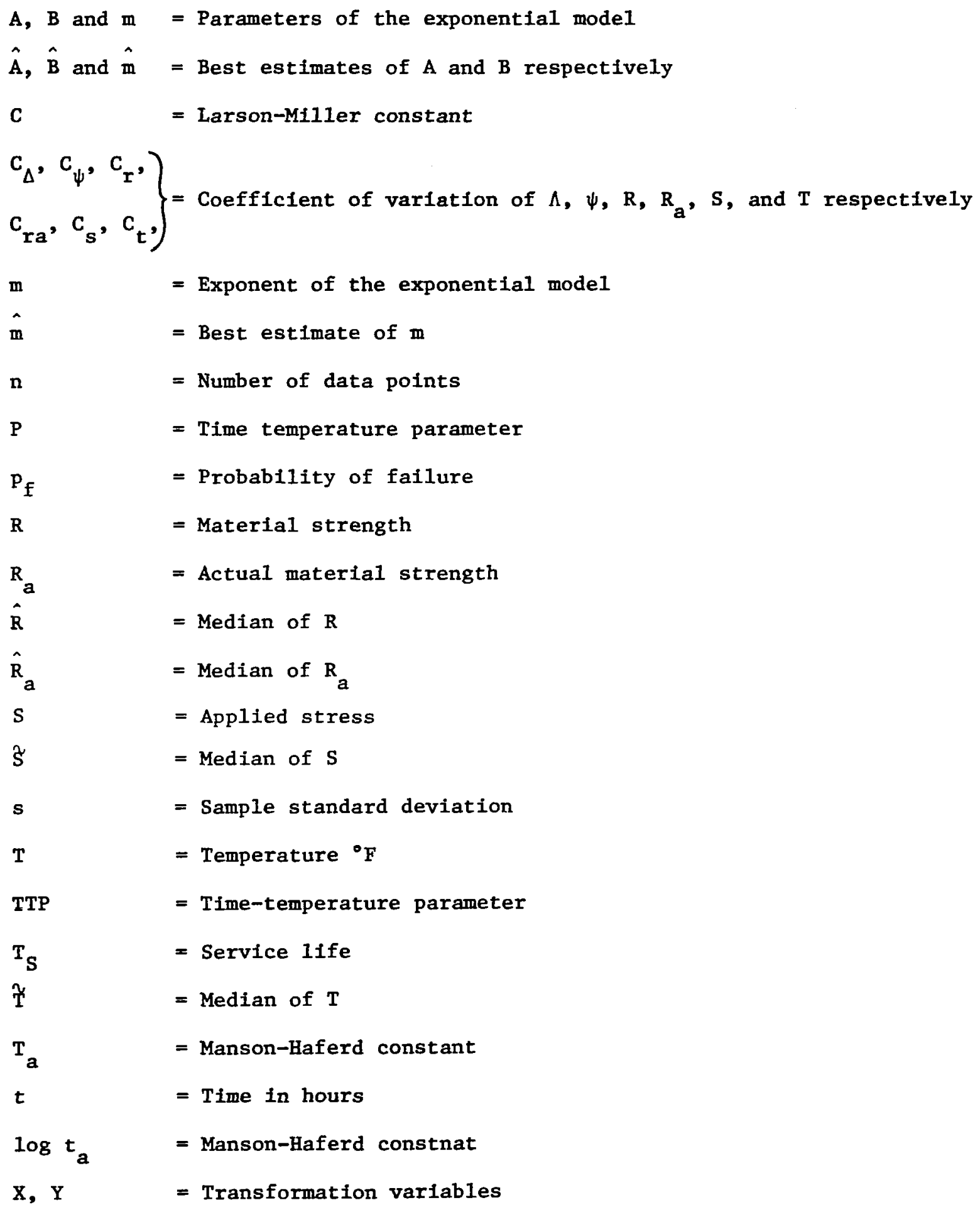




\section{LIST OF GREEK SYMBOLS}

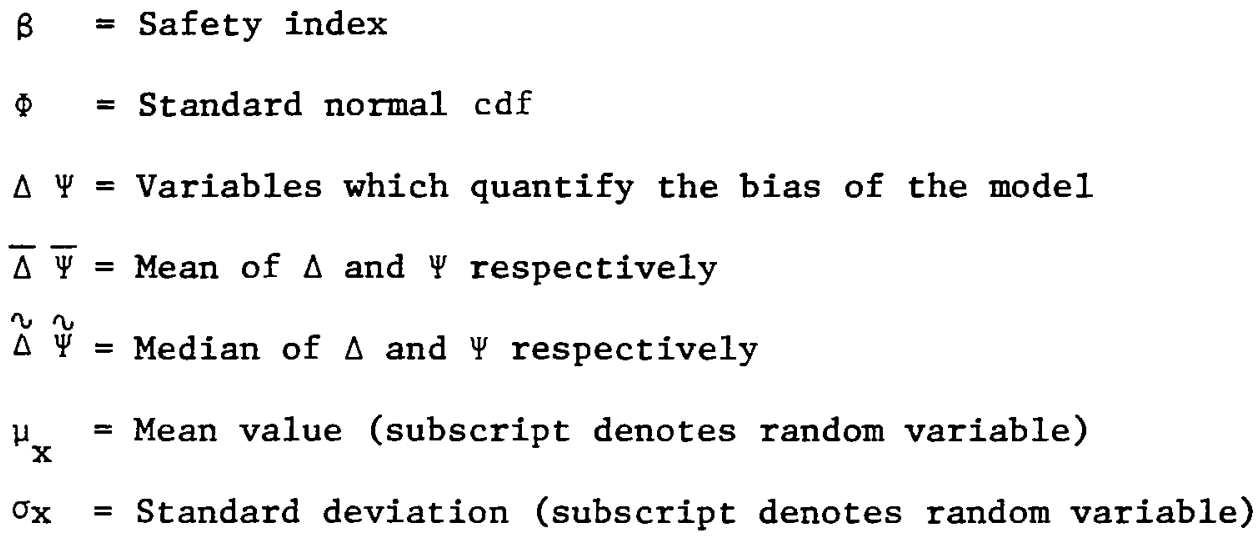




\section{INTRODUCTION}

In 1952 a new approach to the correlation and extrapolation of creeprupture data was introduced [1]. The approach, called the time-temperature parameter (TTP) method, combines time and temperature into a single expression to collapse a family of isothermal curves into a single one. The resulting curve is called the "master curve." The method assures that for a given stress level, rupture (or excessive deformation) will occur at any time and temperature combination which produces a value which corresponds to the value of the TTP at that stress. Various forms of the TTP expression have been introduced. Often mentioned in the literature are the LarsonMiller parameter introduced in 1952 [1]; the Manson-Haferd parameter introduced in 1953 [2]; and the Orr-Sherby-Dorn parameter proposed in 1954 [3]. Another approach is the Minimum Commitment Method, suggested by Manson in 1968 [4]. This method avoids forcing the data to fit a specified TTP. Instead it allows the best fitting parameter to be used. And if none of the known parameters best fit the data, it is capable of developing a new parameter.

Over the years, significant consideration has been given to both physics and mathematics in the development of TTP's. Special emphasis has been in the development of methods for the calculation of empirical constants for the parametric expressions, e.g., the methods presented by Conway [5]. Development of a functional relationship between strength and parameter values, i.e., an analytical representation of the master curve has also been pursued [6]. Simultaneously, studies have been made to assess the effectiveness of the parameter regarding correlation, interpolation and extrapolation of the experimental data (e.g., Goldhoff [7]). The present study applies 
probabilistic design theory to creep-rupture data analysis, bringing state of the art methods to the design of components under creep. It focuses on the development of an analytical representation of the master curve, the calculation of the parameter constants, and the assesment of the effectiveness of the parameters regarding correlation and extrapolation of the data. The Larson-Miller (LM) and the Manson-Haferd (MH) parameters are used in this study, but the methods presented could apply to any of the TTP's. The Larson-Miller parameter is given by the expression

$$
P=(T+460) \quad\left(\log _{10} t+C\right)
$$

and the Manson-Haferd parameter,

$$
P=\frac{T-T a}{\log _{10} t-\log _{10} t_{a}}
$$

where $T$ is temperature in ${ }^{\circ} \mathrm{F}$, $t$ is time in hours. $C, T_{a}$, and $\log _{10} t_{a}$ are corresponding parameters or empirical constants established by the data. The goal of this study was to develop a statistical model for describing creep strength of a material using the TTP concept. This model should quantify scatter in material behavior as well as modelling error. Moreover, the model should be able to fit into a reliability format in which due consideration is given to all sources of uncertainty. Proposed herein is a lognormal model for creep strength and a lognormal format for the general reliabillty problem.

CREEP STRENGTH AND THE MASTER CURVE

Probabilistic design (or mechanical reliability) refers to the process of quantifying uncertainty, and then making decisions so that the risk is 
less than an acceptable value. Risk is assumed herein to be synonymous with probability of failure. Failure of a component under creep can be defined as (a) the event that time to failure is less than the intended service 1ife, or (b) the event that creep strength $R$ is less than the applied stress S, 1.e., $(\mathrm{R}<\mathrm{S})$. The latter definition is adopted here. Figure 1 illustrates the basic problem. Both creep strength and applied stress are considered to be random variables. The risk or probability of failure is defined as

$$
P_{f}=\operatorname{Pr}(R<S)
$$

To evaluate $\mathrm{P}_{f}$, it is necessary to establish the statistical distribution of $R$ and $S$. The process of development of the functional relationship between strength and the TTP also addresses the problem of translating the creeprupture data into a statistical distribution of $R$. The basic relationship proposed here for creep strength is called the "exponential model,"

$$
\log _{10} R=A+B P^{m}
$$

$A, B$, and $m$ are parameters to be determined from the data.

Note: In the case of the IM parameter the value of the parameter $P$ used in the exponential model is in thousands, while for the MH parameter the absolute value of $P$ is used. In the range of interest, $P$ is a negative valued function which can not be raised to a rational power.

The median curve of $R$ given $P$ can be established by a least squares analysis. The model parameters $A, B$ and $m$ are calculated by an iterative procedure. Note that if $\mathrm{m}$ is considered a constant, best linear unbiased estimates of the parameters $A$ and $B$ can be calculated by applying a least 


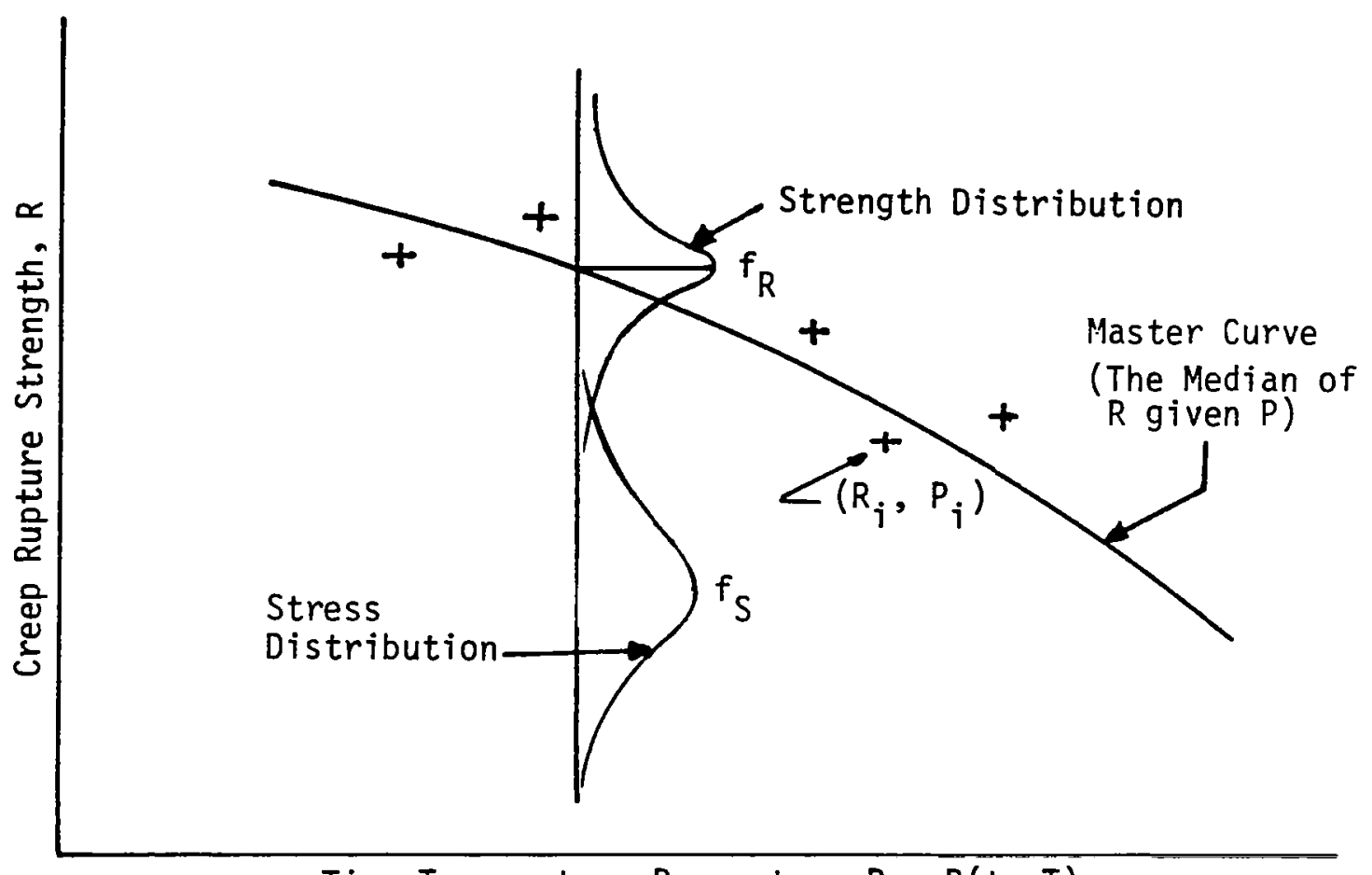

Time Temperature Parameter, $\mathrm{P}=\mathrm{P}(\mathrm{t}, \mathrm{T})$

Figure 1. An Illustration of the Basic Creep Reliability Problem. 
squares analysis to a linearized form of the exponential model [8]. Set

$$
\begin{aligned}
& \mathrm{Y}=\log _{10^{\mathrm{K}}} \\
& \mathrm{X}=\mathrm{P}^{\mathrm{m}}
\end{aligned}
$$

then the exponential model becomes

$$
\mathrm{Y}=\mathrm{A}+\mathrm{BX}
$$

The creep-rupture data $\left(R_{i}, P_{i}\right)$ can be expressed as $\left(y_{i}, x_{i}\right), i=1, n$ using Eqs. 5 and 6 . The least squares line is defined here as those values of $A, B$ and $m$ (denoted as $\hat{A}, \hat{B}$, and $\hat{m}$ ) which minimize the sample standard deviation s. The sample standard deviation is

$$
s=\sqrt{\frac{\sum_{i=1}^{n}\left(y_{i}-\hat{Y}_{i}\right)^{2}}{n-2}}
$$

where

$y_{i}=$ value of $i^{\text {th }}$ point with coordinates $\left(y_{i}, x_{i}\right)$,

$\hat{\mathrm{Y}}_{i}=\hat{\mathrm{A}}+\hat{\mathrm{B}} \mathbf{x}_{\mathbf{i}}$

$\mathrm{n}=$ number of data points.

ESTIMATION OF THE EXPONENTIAL MODEL PARAMETERS AND EVALUATION OF THE TTP CONSTANTS

Evaluation of the TTP constants (e.g., C, Ta, $\log _{10} t_{a}$ ) and the exponential model parameters ( $A, B$, and $m$ ) is achieved using an iterative process. The basic criterion is that the best estimates of all of these material dependent constants are those which minimize the sample standard deviation, s. The numerical procedure is as follows (using Larson-Miller as an example): 
1. Choose an Initial value of $C$.

2. Choose an initial value of $\mathrm{m}$.

3. Use the simple least squares analysis to compute $\hat{A}$ and $\hat{B}$.

4. Compute $s(\mathrm{Eq} .8)$.

5. Repeat steps 2 through 4 until an $\mathrm{m}$ is found (corresponding to your initial choice of $C$ ) which minimizes $s$.

6. Going back to step 1 , repeat the process using another value of $C$. Finally, this procedure produces a minimum $s$ as a function of $\mathrm{C}$.

7. The "best" estimate of $\mathrm{C}$ is defined as that value which corresponds to the minimum value of $s$. The corresponding values $\hat{m}_{3} \hat{A}$, and $\hat{B}$ are estimates of $\mathrm{m}, \mathrm{A}$, and $B$ respectively.

This procedure is easily extended to the case of two (or more) constants. For the MH parameter, steps 1,6 , and 7 are extended to accomodate two constants.

Finally, the "optimum" master curve is

$$
\log _{10} \hat{R}=\hat{A}+\hat{B} P^{\hat{m}}
$$

Examples of this analysis applied to a sample of $\mathrm{n}=95$ Incoloy 625 data are provided in Figs. 2 (for LM) and 3 (for MH). The coherence of the data to the master curve is measured by $C_{R}$, the coefficient of variation of $R$ (proportional to $s$ as given by Eq. 11 below) which defines the vertical scatter. The fact that the $\mathrm{MH}$ analysis produces a slightly lower $C_{R}$ suggests a slightly better fit, . . not surprising in view of the additional constant in the MH parameter.

Table 1 is a summary of the results obtained from an exponential model analysis for five materials. The significance of these results lies in 
Fig. 2. Example of Proposed Analysis Procedure Applied to Incoloy 625 Creep-Rupture Data Using Larson-Miller Parameter.

INCOLOY 625

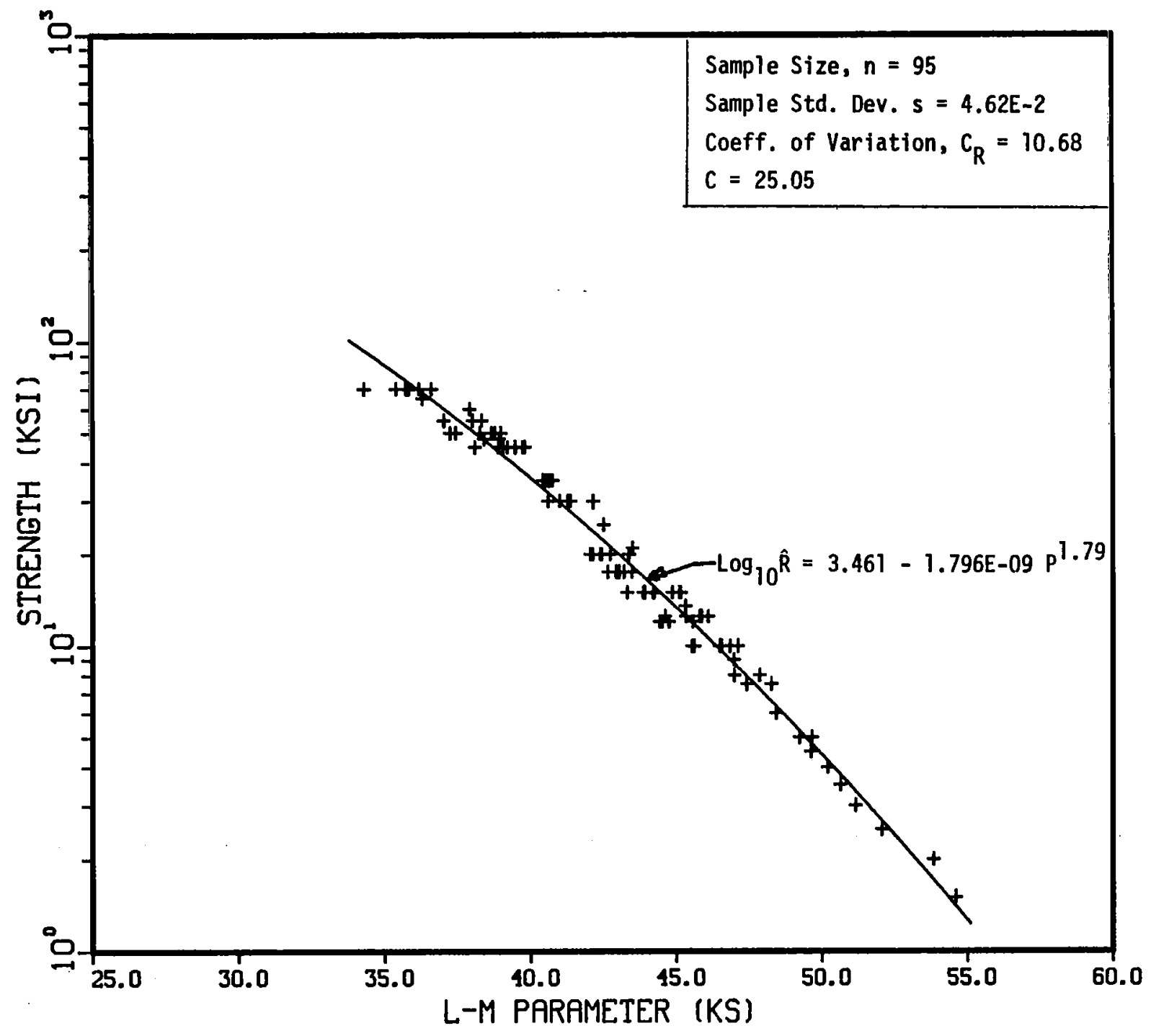


Fig. 3. Example of Proposed Analysis Procedure Applied to Incoloy 625 Creep-Rupture Data Using the Manson-Haferd Parameter.

\section{INCOLOY 625}

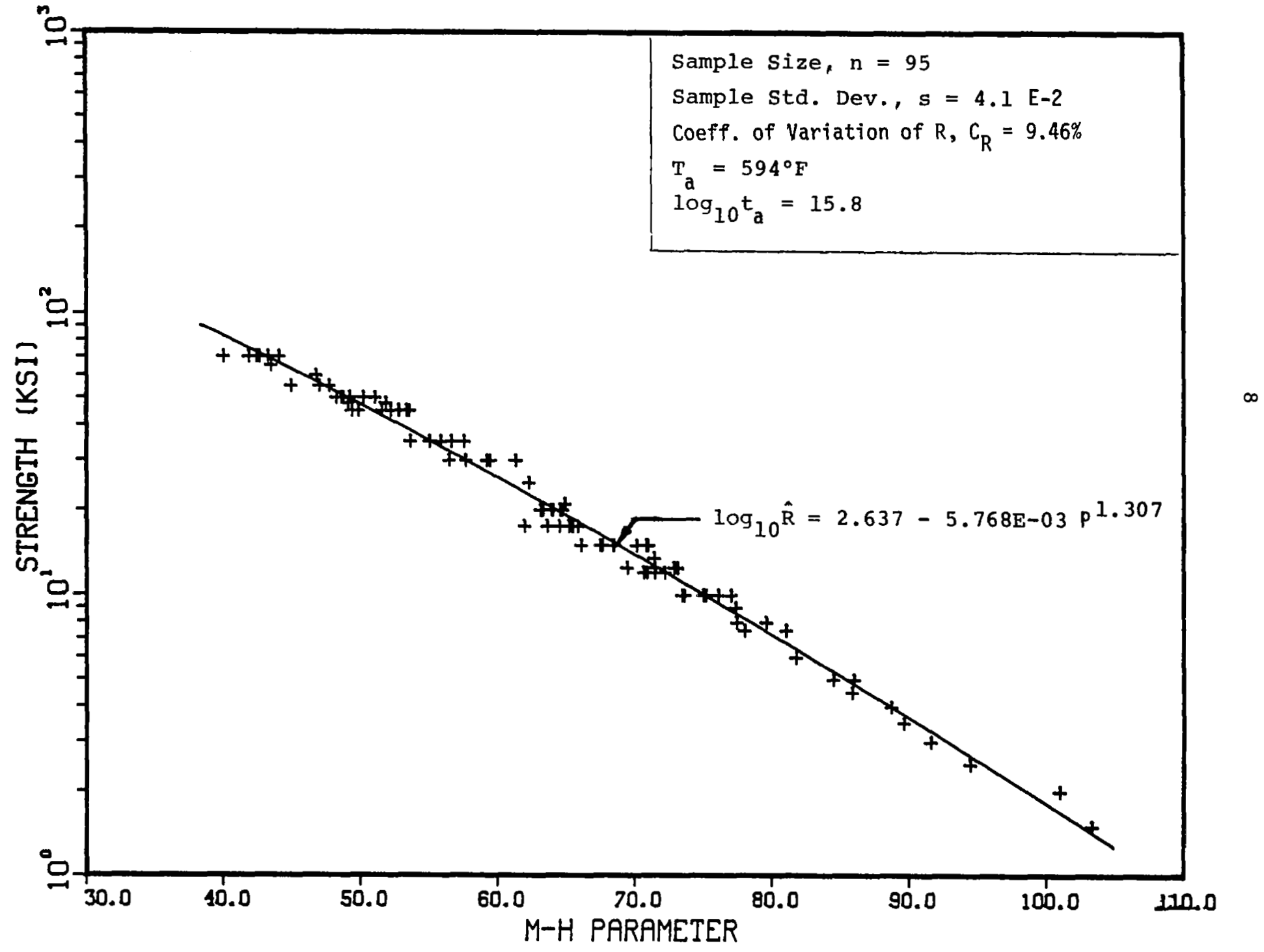


TABLE 1. Summary of Exponential Model Analysis.*

\begin{tabular}{|c|c|c|c|c|c|c|c|c|}
\hline Material & $\stackrel{N}{N}$ & Parameter & $T_{a}, \quad l=\frac{C /}{\log t_{a}}$ & m & A & B & $\stackrel{s}{\times 10^{2}}$ & $\begin{array}{l}\mathrm{C}_{\mathrm{R}} \\
\%\end{array}$ \\
\hline $\begin{array}{l}\text { INCOLOY } \\
\quad 625\end{array}$ & 95 & $\begin{array}{l}\text { LM } \\
\text { MH }\end{array}$ & $\begin{array}{c}25.05 \\
594,15.80\end{array}$ & $\begin{array}{l}1.790 \\
1.307\end{array}$ & $\begin{array}{l}3.461 \\
2.637\end{array}$ & $\begin{array}{l}-1.796 \mathrm{E}-09 \\
-5.768 \mathrm{E}-03\end{array}$ & $\begin{array}{l}4.62 \\
4.10\end{array}$ & $\begin{array}{r}10.68 \\
9.46\end{array}$ \\
\hline $\begin{array}{l}\text { UDIMET } \\
500\end{array}$ & 105 & $\begin{array}{l}\text { LM } \\
\text { MH }\end{array}$ & $\begin{array}{c}22.86 \\
-410,27.05\end{array}$ & $\begin{array}{l}3.877 \\
3.857\end{array}$ & $\begin{array}{l}2.548 \\
2.534\end{array}$ & $\begin{array}{l}-2.591 \mathrm{E}-07 \\
-4.860 \mathrm{E}-08\end{array}$ & $\begin{array}{l}3.55 \\
3.50\end{array}$ & $\begin{array}{l}8.18 \\
8.07\end{array}$ \\
\hline ASTROLOY & 33 & $\begin{array}{l}\text { LM } \\
\text { MH }\end{array}$ & $\begin{array}{c}19.56 \\
618,12.86\end{array}$ & $\begin{array}{l}4.031 \\
2.186\end{array}$ & $\begin{array}{l}2.485 \\
2.375\end{array}$ & $\begin{array}{l}-1.910 \mathrm{E}-07 \\
-3.822 \mathrm{E}-05\end{array}$ & $\begin{array}{l}2.72 \\
2.47\end{array}$ & $\begin{array}{l}6.28 \\
5.68\end{array}$ \\
\hline CR-MO & 33 & $\begin{array}{l}\text { LM } \\
\text { MH }\end{array}$ & $\begin{array}{c}19.18 \\
618,10.70\end{array}$ & $\begin{array}{l}6.928 \\
2.534\end{array}$ & $\begin{array}{l}1.823 \\
1.755\end{array}$ & $\begin{array}{l}-1.077 \mathrm{E}-11 \\
-1.196 \mathrm{E}-05\end{array}$ & $\begin{array}{l}1.17 \\
1.42\end{array}$ & $\begin{array}{l}2.69 \\
3.28\end{array}$ \\
\hline RENE 41 & 37 & $\begin{array}{l}\text { LM } \\
\text { MH }\end{array}$ & $\begin{array}{c}19.09 \\
614,12.21\end{array}$ & $\begin{array}{l}4.205 \\
2.119\end{array}$ & $\begin{array}{l}2.563 \\
2.445\end{array}$ & $\begin{array}{l}-1.407 \mathrm{E}-07 \\
-5.981 \mathrm{E}-05\end{array}$ & $\begin{array}{l}1.87 \\
2.04\end{array}$ & $\begin{array}{l}4.31 \\
4.69\end{array}$ \\
\hline
\end{tabular}

*"Short term" and "long term" data were pooled in the analysis. 
the demonstration that typical values of $C_{R}$ are less than $10 \%$. This value includes both scatter in material behavior and modelling error associated with the use of a TTP. Note that in comparison, scatter in room temperature static properties for most metallic materials is characterized by coefficients of variation of 5 to $10 \%$. Finally, note that the R-P data for all the materials of Table 1, when plotted, would exhibit the same coherence to the master curve as those of Figs. 2 and 3.

\section{A STATISTICAL MODEL FOR CREEP STRENGTH}

Having estimated the model parameters we proceed to construct a statistical model of creep strength $R$. In general, for probabilistic design the model parametera A, B and m could be considered as correlated random variables representing the scatter in the data as well as modelling error. Ensuing reliability analysis, however, would be complicated. It is possible to significantly simplify the analysis by assuming that $A$ is the only random variable. It will account for al.1 material variability and modelling error; $B$ and $m$ are treated as constants. Estimates of the statistics of $A$ are the mean $\mu_{A}=\hat{A}$ and standard deviation $\sigma_{A}=s$. If $A$ is assumed normally distributed, then $\mathrm{R}$ is a lognormally distributed random variable with statistics given by $[10]$,

Median of $R=\tilde{R}=\log _{10}^{-1}\left(\hat{A}+\hat{B} \cdot P^{\hat{m}}\right)$

The coefficient of variation (COV) of $R, \sigma_{R} / \mu_{R}$,

$$
c_{R}=\sqrt{10^{s^{2} / .434-1}}
$$


Note that the master curve of Fig. 2 is in fact $\widetilde{R}$. Also note, as stated above, that $C_{R}=12.3 \%$, given on the figure, is a measure of the vertical scatter.

This form of computing $C_{R}$ ignores the statistical scatter of the estimates. However, it has been found that in the elementary least equares case, the distribution of the estimators does not play a significant role for sample sizes of roughly $n>30$ [10]. For the many available creeprupture data sets of this size or larger, the statistical distribution of the estimates is not expected to be significant.

BIAS AND UNCERTAINTY IN PREDICTING LONG TERM BEHAVIOR FROM SHORT TERM DATA

The ability of a TTP to predict long time behavior (e.g., 20 to 40 years) from short time data (e.g., less than 1 year) is of special interest to designers. A parameter which provides accurate predictions of long time properties would improve current design practices by reducing the risk and/or avoiding overdesign. The ability of a TTP to predict long time behavior can be measured by (a) constructing a model using short term data only, and (b) comparing long term data with the model predictions. Define $\Lambda$ as the ratio of observed to predicted behavior; $\Lambda$ is an index which defines the quality of a model. Following is a mathematical prediction of $\Lambda$ in a form which is suitable for probabilistic design purposes. Define,

$R_{\text {OBS ( } i)}=$ Observed strength (long term data) of $i^{\text {th }}$ specimen $R_{P R E(i)}=\begin{aligned} & \text { Predicted strength of } i^{\text {th }} \text { specimen (model based on short } \\ & \text { term data only) }\end{aligned}$ $\mathrm{n} \quad=$ number of long term data points 
Define $\Lambda$ associated with the $1^{\text {th }}$ specimen as,

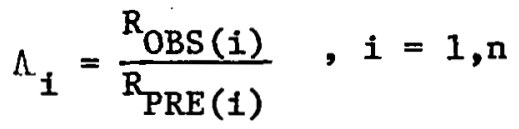

But $\Lambda_{i}$, in general, will be different for each test specimen. Therefore, $\Lambda$ will be a random variable. Compute the sample mean and sample standard deviation as,

$$
\begin{gathered}
\bar{\Lambda}=\frac{1}{n} \sum_{i=1}^{n} \Lambda_{i} \\
s_{\Lambda}=\sqrt{\frac{1}{n-2} \sum_{i=1}^{n}\left(\Lambda_{i}-\bar{\Lambda}\right)^{2}}
\end{gathered}
$$

It is assumed that $\Lambda$ will have a lognormal distribution. In fact, statistical tests (not reported here) show that $\Lambda$ seems to follow an approximate lognormal distribution for many data sets. The median and COV of a lognormal $\Lambda$ will be respectively [10],

$$
\begin{aligned}
& \Lambda=\bar{\Lambda} / \sqrt{1+c_{\Lambda}^{2}} \\
& c_{\Lambda}=s_{\Lambda} / \bar{\Lambda}
\end{aligned}
$$

Note that $\mathrm{C}_{\Lambda}$ measures both scatter in material behavior and strength modelling error. The closer $\bar{A}$ is to unity and the smaller is $s_{\Lambda}$, the better the predictions. If $\bar{\Lambda}<1$, then the model has a tendency to overestimate long time strength. For $\bar{\Lambda}>1$ the strength is underestimated. 
Tables 2 and 3 summarize an exercise to study the behavior of $\Lambda$ from typical creep-rupture data. Models based on the short term data are summarized in Table 2 for various data sets. The bulk of the short term data is less than 1000 hours, with only a few points between 1000 and 3500 hours. Then the mean and cov of the bias in predicting long term behavior for each data set is summarized in Table 3 . Lives of most of the long term data were from 12 to 18 months. The short term and long term data used here was provided by Goldhoff (7). Note that the MH parameter seems to perform much better than the LM parameter as evidenced by the fact that $\bar{\Lambda}$ is consistantly closer to one.

\section{RELIABILITY ANALYSIS}

In general reliability analysis, one should consider all sources of uncertainty including data scatter as well as the bias and distribution of modelling error. Material data scatter is described by the random variable A in the creep rupture analysis. But the bias $\Lambda$ contains both scatter in material behavior and modelling error. In addition, temperature $T$ and stress $\mathrm{S}$ can be treated as random variables reflecting uncertainties in the environment as well as the analysis. The goal of reliability analysis is to synthesize statistical information to compute risk.

For a practical reliability analysis we need an estimate of the

"In service" strength which accounts for data scatter as well as predictive capabilities of the model. Define the actual strength of the material $\mathrm{R}_{\mathrm{a}}$ ?

$$
\mathrm{R}_{\mathrm{a}}=\Psi \mathrm{R}
$$


TABLE 2. Summary of the Analysis of Short Term Data.

\begin{tabular}{|c|c|c|c|c|c|c|c|c|c|}
\hline Material & $\begin{array}{c}\mathrm{N} \\
\text { (short } \\
\text { time) }\end{array}$ & Parameter & $\begin{array}{c}c \\
\mathrm{~T}_{\mathrm{a}}\left({ }^{\circ} \mathrm{F}\right) \\
\log \mathrm{t}_{\mathrm{a}}\end{array}$ & $\mathrm{m}$ & A & B & $\stackrel{s}{\times 10^{2}}$ & $\begin{array}{l}\mathrm{C}_{\mathrm{R}} \\
\%\end{array}$ & $\begin{array}{l}\text { Time less } \\
\text { than (days) }\end{array}$ \\
\hline \multirow{2}{*}{$\begin{array}{l}\text { Iricoloy } \\
625\end{array}$} & \multirow[t]{2}{*}{78} & $\mathrm{LM}$ & 32.11 & 1.616 & 3.698 & $-2.737 \mathrm{E}-03$ & 4.19 & 9.68 & 145 \\
\hline & & MH & $815,13.40$ & 1.221 & 2.377 & $-7.526 \mathrm{E}-03$ & 3.84 & 8.86 & \\
\hline \multirow{2}{*}{$\begin{array}{l}\text { UDIMET } \\
500\end{array}$} & \multirow[t]{2}{*}{93} & $L M$ & 24.11 & 3.954 & 2.534 & $-1.549 \mathrm{E}-07$ & 3.60 & 8.31 & 19 \\
\hline & & MH & $-545,29.24$ & 4.108 & 2.540 & $-1.749 \mathrm{E}-08$ & 3.65 & 8.41 & \\
\hline \multirow{2}{*}{$\begin{array}{l}\text { UDIMET } \\
500\end{array}$} & \multirow[t]{2}{*}{66} & $\mathbf{L M}$ & 26.27 & 4.408 & 2.462 & $-1.643 \mathrm{E}-08$ & 3.60 & 8.30 & 139 \\
\hline & & MH & $-554,30.50$ & 4.572 & 2.470 & $-2.517 \mathrm{E}-09$ & 3.62 & 8.34 & \\
\hline \multirow[t]{2}{*}{ ASTROLOY } & \multirow[t]{2}{*}{21} & LM & 24.60 & 5.084 & 2.324 & $-9.570 \mathrm{E}-10$ & 1.61 & 3.72 & 23 \\
\hline & & MH & $600,14.71$ & 2.853 & 2.236 & $-2.240 \mathrm{E}-06$ & 1.88 & 4.43 & \\
\hline \multirow[t]{2}{*}{ RENE 41} & \multirow[t]{2}{*}{26} & $\mathrm{LM}$ & 20.34 & 4.582 & 2.505 & $-2.476 \mathrm{E}-08$ & 1.69 & 3.89 & 32 \\
\hline & & MH & $609,12.08$ & 2.360 & 2.395 & $-1.808 \mathrm{E}-05$ & 1.83 & 4.22 & \\
\hline \multirow[t]{2}{*}{ CR-MO } & \multirow[t]{2}{*}{23} & $\mathrm{LM}$ & 20.57 & 6.484 & 1.852 & $-3.701 \mathrm{E}-11$ & 0.867 & 2.00 & 90 \\
\hline & & MH & $618,10.17$ & 2.592 & 1.756 & $-7.878 \mathrm{E}-06$ & 0.843 & 1.94 & \\
\hline \multirow{2}{*}{$\begin{array}{l}\text { HASTELLOY } \\
\mathrm{X}\end{array}$} & \multirow[t]{2}{*}{29} & LM & 18.59 & 0.940 & 4.683 & $-1.082 \mathrm{E}-01$ & 3.54 & 8.16 & 37 \\
\hline & & MH & $614,11.08$ & 0.834 & 2.905 & $-3.777 \mathrm{E}-02$ & 3.54 & 8.18 & \\
\hline \multirow[t]{2}{*}{$316-S S$} & \multirow[t]{2}{*}{28} & LM & 17.93 & 2.746 & 2.337 & $-5.714 \mathrm{E}-05$ & 1.26 & 2.89 & 38 \\
\hline & & MH & $618,10.06$ & 1.414 & 2.106 & $-1.444 E-03$ & 1.35 & 3.12 & \\
\hline \multirow[t]{2}{*}{$L-605$} & \multirow[t]{2}{*}{76} & LM & 18.79 & 3.210 & 2.167 & $-5.476 \mathrm{E}-06$ & 1.92 & 4.42 & 40 \\
\hline & & MH & $583,17.27$ & 1.761 & 2.050 & $-2.113 E-04$ & 2.50 & 5.75 & \\
\hline \multirow[t]{2}{*}{$A 1-1100$} & \multirow[t]{2}{*}{53} & LM & 18.04 & 1.056 & 2,274 & $-8.968 \mathrm{E}-02$ & 1.34 & 3.08 & 17 \\
\hline & & MH & $-499,22.92$ & 1.056 & 2.355 & $-3.569 \mathrm{E}-02$ & 1.42 & 3.28 & \\
\hline
\end{tabular}


TABLE 3. Statistics of $\Lambda$ Exhibited by the TTP's.

\begin{tabular}{|l|c|c|c|c|c|c|}
\hline \multicolumn{1}{|c|}{ MATERIAL } & \multicolumn{2}{|c|}{ LM } & \multicolumn{2}{c|}{ MH } & \multicolumn{2}{c|}{ Number of Data Points } \\
\hline & $\bar{\Lambda}$ & $C_{\Lambda} \%$ & $\bar{\Lambda}$ & $C_{\Lambda} \%$ & $\begin{array}{c}\text { Short } \\
\text { Time }\end{array}$ & $\begin{array}{c}\text { Long } \\
\text { Time }\end{array}$ \\
\hline INCOLOY 625 & 0.477 & 15.6 & 0.941 & 12.00 & 78 & 17 \\
\hline UDTMET 500 & 0.928 & 5.27 & 0.972 & 3.95 & 93 & 12 \\
\hline UDIMET 500 & 0.904 & 7.69 & 0.939 & 6.93 & 66 & 37 \\
\hline ASTROLOY & 0.884 & 9.52 & 0.928 & 8.65 & 21 & 12 \\
\hline RENE 41 & 0.971 & 6.22 & 1.022 & 8.19 & 26 & 11 \\
\hline CR-MO & 0.967 & 4.99 & 1.059 & 8.98 & 23 & 10 \\
\hline HASTELLOY-X & 0.920 & 15.6 & 0.993 & 19.0 & 29 & 18 \\
\hline 316-SS & 1.037 & 8.25 & 1.125 & 9.45 & 28 & 10 \\
\hline L-605 & 0.668 & 15.0 & 1.130 & 17.8 & 76 & 28 \\
\hline A1-1100 & 1.036 & 6.07 & 1.055 & 7.38 & 53 & 11 \\
\hline
\end{tabular}


where $\Psi$ is a random variable which accounts for bias and uncertainty of modelling error associated with using a TTP to extrapolate. $R$ is the predicted strength of the material as calculated from the exponential model, Eq. 4, as

$$
R=\log _{10}^{-1}\left(A+B P^{m}\right)
$$

where $P=P(t, T)$. $R$ is a random variable because $A$ and $T$ are random variables. Note that if $\mathrm{T}$ is assumed to be constant and $\mathrm{A}$ is normally distributed, then $R$ would have an exact lognormal.

The statistics of $\Psi$ are established as follows. First it is assumed that $T=$ constant in the data used to compute $\tilde{\Lambda}$ and $C_{\Lambda}$. Then assume that $\Psi$ is lognormal. $R_{a}$ will have exact lognormal with statistics

$$
\begin{gathered}
\text { Median, }{\stackrel{\sim}{R_{a}}=\stackrel{\sim}{\Psi}}_{\mathrm{R}}^{\sim} \\
\text { cov, } \mathrm{C}_{\mathrm{R}_{\mathrm{a}}}=\sqrt{\left(1+\mathrm{C}_{\Psi}^{2}\right)\left(1+\mathrm{C}_{\mathrm{R}}^{2}\right)-1}
\end{gathered}
$$

Now $\Lambda$ contains both data scatter and modelling error so that $C_{R_{a}}=C_{\Lambda}$. Also note that

$$
\tilde{R}_{\mathbf{a}}=\tilde{\Lambda} \mathbf{R}
$$

Comparing Eqs. 19 and 21 and solving for $C_{\Lambda}$ in Eq. 20, the statistics for $\Lambda$ are

$$
\begin{gathered}
\tilde{\psi}=\tilde{\Lambda} \\
\mathrm{c}_{\Psi}=\sqrt{\frac{1+\mathrm{C}_{\grave{\Lambda}}^{2}}{1+\mathrm{c}_{\mathrm{R}}^{2}}}-1
\end{gathered}
$$

What we have done is to extract uncertainty due to modelling error from A. Thus, $C_{\Psi}$ describes modelling error in the use of the TTP. 
Consider a simple example which illustrates how to separate material variability from modelling error associated with using a TTP to extrapolate to long times. Use of the LM parameter on Incoloy 625 is demonstrated. $C_{R}$ is established from short term data as 0.0968 (See Table 2). From long term data (Table 3), $\bar{\Lambda}=0.477$ and $c_{\Lambda}=0.156$. The median of $\Lambda$ is computed from Eq. 15 as $\tilde{\Lambda}=0.471$. Thus, $\tilde{\Psi}=0.471$. From Eq. $22, c_{\Psi}=0.121$. Thus, statistics on modelling error and material behavior are separated.

It should be noted that $C_{\Lambda} \geq C_{R}$ with equality when there is no modelling error due to extrapolation. The fact that $C_{R}$ exceeds $C_{\Lambda}$ in some of the data sets of Table 2 and 3, suggests that sample sizes were inadequate. Furthermore, note that $C_{R}$ contains some modelling error. The use of a TTP to describe a complex material phenomena suggests only an approximation to physical reality. However, because the values of $C_{R}$ (less than $10 \%$ ) do not significantly differ from those of other static properties, it is likely that this component of modelling error is small.

If both the distributions of stress, $S$ and $R_{a}$ are lognormal, a closed form expression for probability of failure is available [10]. The probability of failure is

$$
\mathrm{p}_{\mathrm{f}}=\Phi(-\beta)
$$

where $\Phi$ is the standard normal cdf, and $\beta$ is the safety index, as given by

$$
\beta=\frac{\ln \left(\tilde{\mathrm{R}}_{\mathrm{a}} / \tilde{S}\right)}{\sqrt{\ln \left[\left(1+\mathrm{C}_{\mathrm{S}}^{2}\right)\left(1+\mathrm{C}_{\mathrm{R}_{\mathrm{a}}}^{2}\right)\right.}}
$$

$\sim$

$S$ and $C_{S}$ are the median and $\operatorname{COV}$ of $S$ respectively. 
In the more general case where $T$ is also considered to be a random variable, reliability analysis becomes much more difficult. Techniques such as Monte Carlo or Rackwitz-Fiessler method [10,12] must be employed to relate risk to the design parameters.

It is important to note that computed values of $p_{f}$ should be considered as "notional" values of the probability of failure. Because of the many uncertainties and assumptions and because risk levels are so low, it may be imprudent to argue that $p_{f}$ defines risk levels in an actuarial sense.

\section{DEMONSTRATION OF RELIABILITY ANALYSIS}

Example 1. It is required to design a tension element to the following specifications (a) the temperature is $1100^{\circ} \mathrm{F}\left(593^{\circ} \mathrm{C}\right)$, (b) the life of the component is 40 years $(350,000 \mathrm{hrs})$, (c) the applied load is lognormally distributed with statistics $\stackrel{\sim}{P}=10$ kips $(44.48 \mathrm{kN})$ and $C_{P}=25 \%$. The material considered is Hastelloy $x$. The problem is to find the component's minimum cross-sectional area $A$ if the maximum allowable risk is $p_{f}=10^{4}$. From normal tables the target safety index is $\beta=-\Phi^{-1}\left(p_{f}\right)=3.72$. In this problem both the LM and MH parameters will be used. The relationship of load to stress is $\mathrm{S}=\mathrm{P} / \mathrm{A}$, hence $\mathrm{C}_{\mathrm{S}}=\mathrm{C}_{\mathrm{P}}=25 \%$.

a) Larson-Miller Analysis

The optimized form of the IM parameter for Hastelloy $\mathrm{X}$ is given by (See Table 2)

$$
P=(T+460)\left(\log _{10} t+18.59\right)
$$

In this example

$$
P=(1100+460)\left(\log _{10} 350,000+18.59\right)=37.65 \text { thousands }
$$


Using the data from Table 2 in Eq. 4, predicted strength is

$$
\begin{aligned}
\log _{10} \dddot{R} & =4.683-0.1082(37.65)^{0.940} \\
\dddot{R} & =25.48 \mathrm{ksi}(175.7 \mathrm{MPa})
\end{aligned}
$$

The median and COV of the actual strength $R_{a}$ is obtained using the data of Table 3. Note that (a) both modelling error and material behavior are included and (b) the median of $\Lambda$ is obtained using Eq. 15 .

$$
\begin{aligned}
\mathrm{C}_{\mathrm{Ra}} & =\mathrm{C}_{\Lambda}=15.6 \% \\
\tilde{R}_{a}=\tilde{\Lambda} \mathrm{R} & =0.909 \cdot 25.48 \mathrm{ksi}=23.16 \mathrm{ksi}(159.67 \mathrm{MPa})
\end{aligned}
$$

Rearranging Eq. 24, $\tilde{\mathrm{S}}$ is given by

$$
\tilde{\mathbf{S}}=\frac{\widetilde{R}_{a}}{\exp \left\{\beta\left[\ln \left(1+\mathrm{C}_{\mathrm{Ra}}^{2}\right)\left(1+\mathrm{C}_{\mathrm{S}}^{2}\right)\right]^{\frac{1}{2}}\right\}}
$$

Then,

$$
\widetilde{S}=\frac{23.16}{\exp \left\{3.72\left[\ln \left(1+.156^{2}\right)\left(1+.25^{2}\right)\right]^{\frac{1}{2}}\right\}}=7.82 \mathrm{ks} 1(53.91 \mathrm{MPa})
$$

For a safe design the minimum required area is

$$
A \geq \frac{P}{S}=\frac{10}{7.82}=1.28 \mathrm{in}^{2}\left(8.25 \mathrm{~cm}^{2}\right)
$$

b) The Manson-Haferd Analysis

The MH parameter for Hastelloy $X$ is given by (see Table 2)

$$
P=\left|\frac{T-614}{\log t-11.08}\right|=87.8
$$

Using data from Table 2 in Eq. 4, predicted strength is

$$
\begin{aligned}
\log _{\mathrm{N}} \widetilde{R} & =2.905-3.777 \mathrm{E}-02(87.8) 0.834 \\
\widetilde{R} & =21.25 \mathrm{ksi}(146.51 \mathrm{MPa})
\end{aligned}
$$


The median and COV of the actual strength is obtained from Table 3. n

$\Lambda$ is computed using Eq. 15 .

$$
\begin{gathered}
c_{\mathrm{Ra}}=C_{\Lambda}=19.0 \% \\
\widetilde{\mathrm{R}}_{\mathrm{a}}=\tilde{\Lambda} \tilde{\mathrm{R}}=0.979 \cdot 21.25 \mathrm{ksi}=20.8 \mathrm{ksi}(143.40 \mathrm{MPa})
\end{gathered}
$$

Then, as above, the maximum allowable stress is

$$
\tilde{S}=\frac{20.8}{\exp \left\{3.72\left[\ln \left(1+.19^{2}\right)\left(1+.21^{2}\right)\right]^{\frac{1}{2}}\right\}}=6.55 \mathrm{ksi}(45.18 \mathrm{MPa})
$$

For a safe design, the requirement on the area is

$$
A \geq P / S=10 / 6.55=1.53 \mathrm{in}^{2}\left(9.85 \mathrm{~cm}^{2}\right)
$$

We are incapable of providing a commentary at this point regarding the poor agreement between the design as established by each parameter. From intuition, however, it seems reasonable to place more confidence in MH simply becuase it contains two (rather than one) empirical constants.

Example 2. As an extension to Example 1, assume now that uncertainties in the temperature analysis are to be considered. It is estimated that the median (best estimate) of $\mathrm{T}$ is $1100^{\circ} \mathrm{F}$ and $\operatorname{cov}$ of $\mathrm{T}$ is $5 \%$. The member chosen has a cross sectional area of $1.60 \mathrm{in}^{2}\left(10.3 \mathrm{~cm}^{2}\right)$, larger than the $1.53 \mathrm{in}^{2}\left(9.85 \mathrm{~cm}^{2}\right)$ required in the constant $\mathrm{T}$ case. Does the design satisfy the basic requirement that the target safety index, $\beta>3.72$ ?

A closed form solution is not available. To solve this problem, a numerical method, the Rackwitz-Fiessler (R-F) method will be employed $[10,12]$. The computer program requires the limit state as input.

$$
(S=\Psi R)=\left(S=\Psi \cdot \log _{10}^{-1}\left\{A+B\left[(T+460)\left(\log _{10} t+18.59\right)\right]^{m_{3}}\right\}\right.
$$


$S, A$ and $T$ are random variables. It is clear that the computation of the probability of failure event would be most difficult by classical methods.

The computations are summarized in Table 4 . The computed safety index, $\beta=3.33$, is less than the target safety index $\beta_{0}=3.72$, so the design is considered to be unsafe. It is interesting to note that if we let $C_{T} \rightarrow 0(T=\tilde{T}$, a constant), then the safety index is $B=4.50$. Clearly reliability is sensitive to uncertainties in $T$.

We can also compute the notional probability of failure as

$$
p_{f}=\Phi(-\beta)
$$

For $B=3.33, P_{f}=4.36 \mathrm{E}-4$, and for $B=4.50, \mathrm{P}_{\mathrm{f}}=3.44 \mathrm{E}-6$. CONCLUSIONS

A general method for reliability analysis of creep rupture data is presented. The method employs the time-temperature parameter (TTP) concept. An exponential model, $\log _{10} R=A+B P^{m}$, relating strength $R$, to $P$, the TTP, was shown to provide a good fit to creep-rupture data. Evidence of the quality of the exponential model is provided by the low values of the coefficient of variation of $\mathrm{R}$ in Table 2 (typically less than 10\%). Furthermore, the exponential model fits well into a probabilistic design format.

In general, the assumption that all of the statistical scatter of the data can be lumped into $A$ is valid only when the data is homoscedastic (constant scatter band). This data is not always homoscedastic when the universal constants associated with each TTP are used. 
TABLE 4. Summary of the Input and Output of the UA Reliability Program (a) to Calculate $\beta$.

Data

\begin{tabular}{|c|l|c|c|c|c|}
\hline Variable & Distribution & Mean & Median & COV\% & $\sigma$ \\
\hline $\mathrm{S}$ & Lognormal & & 6.25 & 25.0 & \\
\hline $\mathrm{A}^{(\mathrm{b})}$ & Normal & 4.683 & & 8.2 & 0.382 \\
\hline $\mathrm{T}$ & Lognormal & & 1100 & 5.0 & \\
\hline$\Psi$ & Lognormal & & $0.909^{(\mathrm{c})}$ & $13.3^{(\mathrm{d})}$ & \\
\hline
\end{tabular}

Safety Index, $\beta=3.327$

Notional Probability or Failure, $P_{f}=4.40 E-4$

Design Point (approximately most probable value on the limit state function; close to the peak of the joint probability density function of the design factors)

$\mathrm{S}^{*}=7.57$

$A^{*}=4.674$

$\mathrm{T}^{*}=1329$

$\Psi^{*}=0.857$

Notes

(a) This program has the option of using the Hasofer-Lind, Rackwitz-Fiessler or Chen-Lind method for computing the generalized safety index.

(b) Hastelloy $\mathrm{X}$; See Table 2 .

$\sim 2 n$

(c) $\Psi=\Lambda$; and $\Lambda$ obtained using Eq. 15 and data of Table 2 .

(d) Computed using data of Tables 2 and 3 and Eq. 22. 
The assumption that $\mathrm{A}$ is normally distributed is a matter of convenience for the reliability analysis. While no formal goodness of fit test was used, the normal assumption for A seems to be very reasonable on the basis of visual inspection of R-P plots.

Investigation of the bias in predicting long term behavior from short term data of both the LM and MH parameters suggest that both do a fair job. But no general trend was observed. Probability plots of $\Lambda$, and hence $\Psi$, suggest that $\Lambda$ (and $\Psi$ ) follows a distribution close to a lognorma1.

Finally, failure is not always defined as rupture. It can be defined as excessive deformation. When this is the case, a similar approach to the one presented above is possible. Time to failure would indicate time to achieve a predetermined deformation, say 1,2 , or $5 \%$ creep. Creep strength would now be defined as stress, e.g., for 1,2 , or $5 \%$ creep strain. Fig. 4 illustrates the master curves for creep rupture and $1 \%$ strain. 
Fig. 4. Analysis of $1 \%$ Creep Strain Data. Creep Strain Data was Plotted by Using Optimized L-M Constant for Creep Rupture.

ASTROLOY

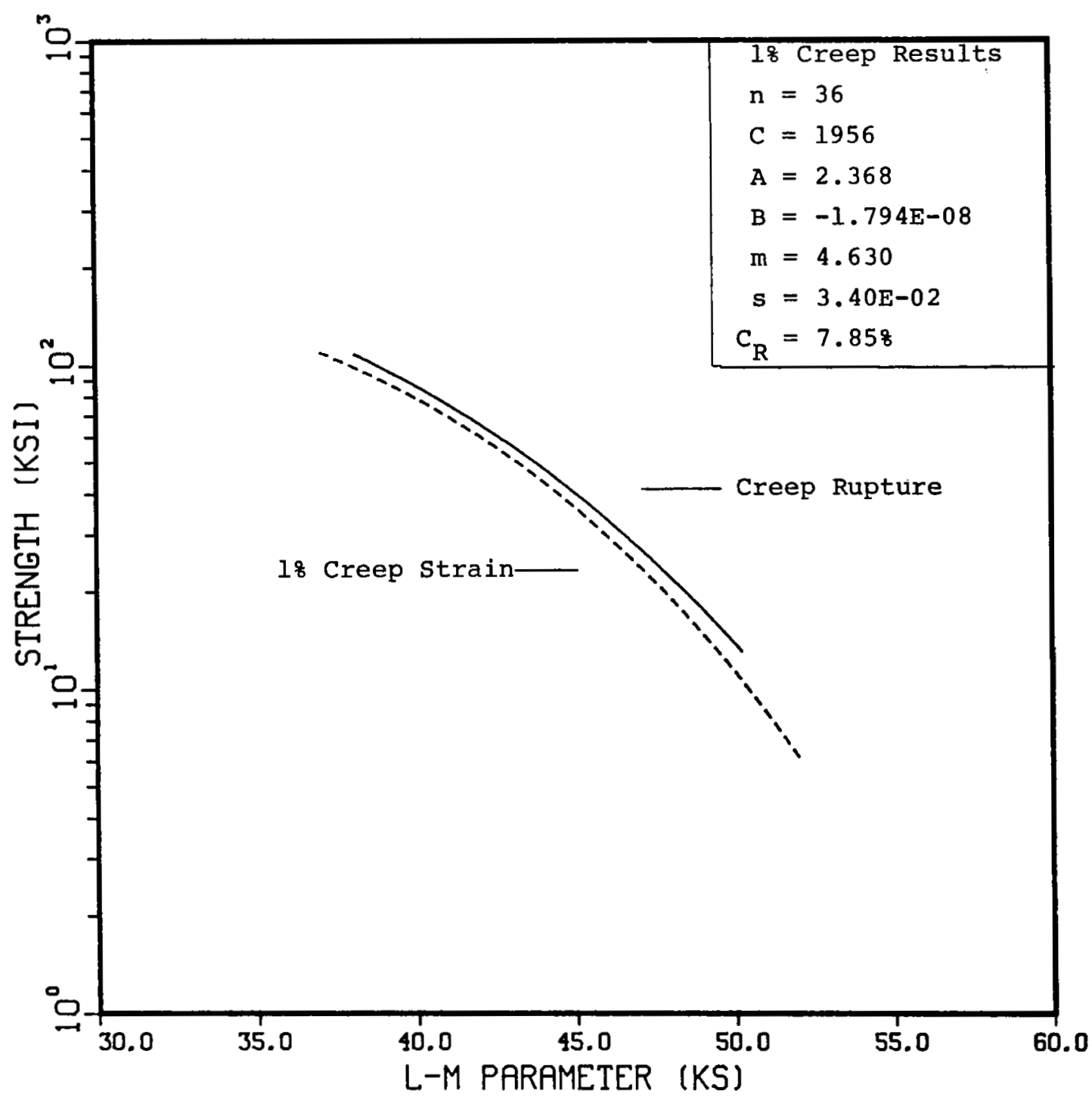


REFERENCES

1. Larson, F. R. and Miller, J., "A Time-Temperature Relationship for Rupture and Creep Stress," Transactions ASME, Vo1. 74, 1952, p. 765.

2. Manson, S. S. and Haferd, A. M., "A Linear Time-Temperature Relation for Extrapolation of Creep and Stress Rupture Data," NACA TN 2890. 1953.

3. Orr, R. L., Sherby, O. D. and Dorn, J. E., "Correlation of Rupture Data for Metals at Elevated Temperatures," Transactions ASME, Vo1. 46, 1954, p. 113.

4. Manson, S. S., "Time Temperature Parameters - A Re-evaluation and Some New Approaches," ASM Publication No. D8-100, 1968.

5. Conway, J. B., Stress-Rupture Parameters: Origin Calculation and Use, Gordon and Breach, Science Publishers, Ltd., London, 1969.

6. Grounes, M., "A Reaction Treatment of the Extrapolative Methods in Creep Testing," Transactions ASME, Journal of Basic Engineering, March 1969, p. 59.

7. Goldhoff, R. M., "Towards the Standardization of Time-Temperature Parameter Usage in Elevated Temperature Data Analysis," Journal of Testing and Evaluation, JTEVA, Vol. 2, No. 5, Sept. 197, pp. 387-424.

8. Hines, W. W. and Montgomery, D. C., Probability and Statistics in Engineering and Management Sciences, John Wiley \& Sons, New York, 1980.

9. Manson, S. S. and Ensign, C. R., "A Quarter Century of Progress in the Development and Extrapolation Methods for Creep Rupture Data," Journal of Engineering Materials and Technology, Vol. 101, Oct. 1979, p. 317 .

10. Wirsching, P. H., "Application of Probabilistic Design Theory to High Temperature Low Cycle Fatigue," NASA CR-165488, NASA Lewis Research Center, Cleveland, OH., Nov. 1981.

11. Hahn, G. J., "Statistical Methods for Creep, Fatigue and Fracture Data Analysis," Transactions ASME, Journal of Engineering Materials and Technology, Vol. 101, Oct. 1979, PP. 344-348.

12. Thoft-Christensen, P., Baker, M. J., Structural Reliability Theory and Its Applications, Springer-Verlag, N. Y., 1982.

13. Wu, Y. T., McLain, S. D., Kelly, C. F., and Wirsching, P. H., "On the Performance of the Rackwitz-Fiessler and Chen-Lind Algorithms for Computing Structural Reliability," The University of Arizona, Sero. and Mech. Engr. (manuscript in preparation), 1983. 
14. Clough, W. R. and Kaut, P. K., "Computerized Evaluation of the Relative Properties of Seven Time Temperature Parameters to Correlate and Extrapolate Nickel Alloy Stress-Rupture Data," Transactions ASME, Journal of Basic Engineering, March 1972, p. 7.

15. Goldhoff, R. M., "Comparison of Parameter Methods of Extrapolating High Temperature Data," Transactions ASME, Journal of Basic Engineering, Dec., 1959, p. 629.

16. Manson, S. S. and EnsIgn, C. R., "Interpolation and Extrapolation of Creep Rupture Data by the Minimum Commitment Method - Part I - FocalPoint Convergence," NASA TM-78881, 1978.

17. Manson, S. S. and Ensign, C. R., "Interpolation and Extrapolation of Creep Rupture Data by the Minimum Commitment Method - Part II Oblique Translation," NASA TM-78882, 1978.

18. Manson, S. S. and Ensign, C. R., "Interpolation and Extrapolation of Creep Rupture Data by the Minimum Commitment Method - Part III Analysis of Multiheats," NASA TM-78883, 1978. 


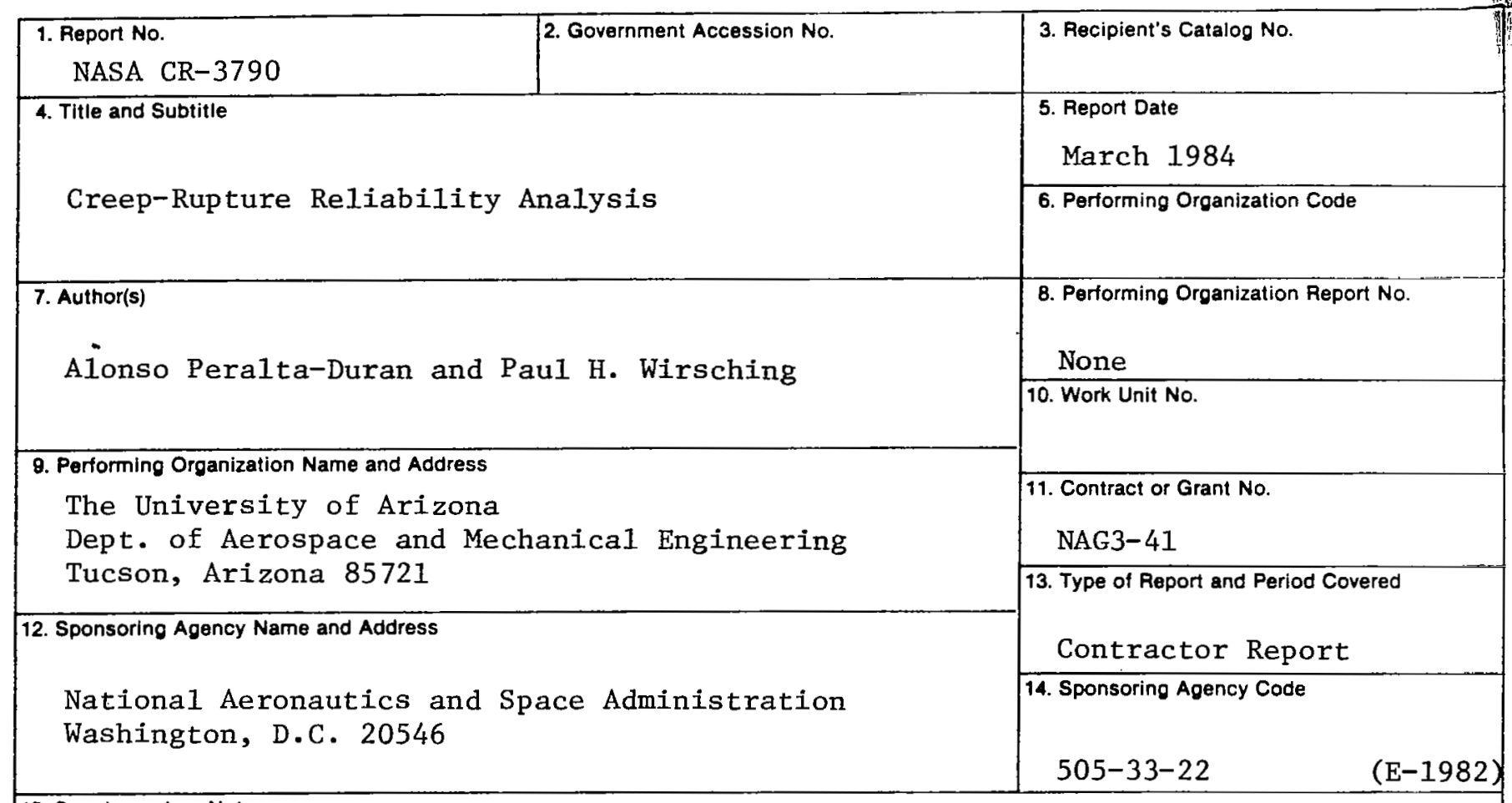

15. Supplementary Notes

Final report. Project Manager, Charles R. Ensign, Project Management and Coordination Office, NASA Lewis Research Center, Cleveland, Ohio 44135.

\section{Abstract}

A probabilistic approach to the correlation and extrapolation of creep-rupture data is presented. Time temperature parameters (TTP) are used to correlate the data, and an analytical expression for the master curve is developed. The expression provides a simple model for the statistical distribution of strength and fits neatly into a probabilistic design format. The analysis focuses on the Larson-Miller and on the Manson-Haferd parameters, but it can be applied to any of the TTP's. A method is developed for evaluating material dependent constants for TTP's. It is shown that "optimized" constants can provide a significant improvement in the correlation of the data, thereby reducing modelling error. Attempts were made to quantify the performance of the proposed method in predicting long term behavior. Uncertainty in predicting long term behavior from short term tests was derived for several sets of data. Examples are presented which illustrate the theory and demonstrate the application of state of the art reliability methods to the design of components under creep.

\footnotetext{
17. Koy Words (Suggested by Author(s))

Stress rupture; Time-temperature parameter; Creep rupture;

Statistical models; Extrapolation; Larson-Miller parameter
}

18. Distribution Statement

Unclassified - unlimited

STAR Category 39

19. Security Classif. (of this report)

Unclassified

$\mid \begin{gathered}\text { 20. Securfty Classif. (of this pago) } \\ \text { Unclassified }\end{gathered}$

21. No. of pages
30

22. Price" $\mathrm{A} 03$

-For sale by the National Tochnical Information Servlce, Springfield, Virginia 22161 